\title{
Predicting the effect of anthelmintic treatment on milk production of dairy cattle in Canada using an Ostertagia ostertagi ELISA from individual milk samples
}

\author{
Raphaël Vanderstichel ${ }^{*}, 1$, Ian Dohoo ${ }^{1}$, Javier Sanchez ${ }^{1}$, Fortune Sithole ${ }^{2}$, \\ Gregory Keefe ${ }^{1}$, Henrik Stryhn ${ }^{1}$ \\ ${ }^{1}$ Department of Health Management, Atlantic Veterinary College, University of Prince \\ Edward Island, 550 University Avenue, Charlottetown, PEI, Canada C1A 4P3 \\ ${ }^{2}$ Department of Paraclinical Sciences, Faculty of Veterinary Science, University of Pretoria, \\ Private Bag X04, Onderstepoort 0110, Republic of South Africa \\ * Corresponding author. Tel.: 902566 6006; fax: 9025660823. \\ E-mail address: rvanderstich@upei.ca (R. Vanderstichel)
}

\begin{abstract}
Gastrointestinal nematodes, such as Ostertagia ostertagi and several species of Cooperia, are ubiquitous in temperate climates and have been shown to have detrimental effects on production in adult dairy cattle. A published meta-analysis demonstrated that overall, producers lose approximately $0.35 \mathrm{~kg}$ of milk per parasitized cow per day. Enzyme-linked immunosorbent assays (ELISAs) have the ability to quantify nematode infections in cattle, and thus, could be used to estimate the amount of milk production loss due to differing levels of parasitism at the individual cow level.
\end{abstract}


ELISA results from individual cow milk samples were used to predict milk production response following a randomized anthelmintic treatment in a large field trial. To increase statistical power, the data collected from this field trial was pooled with data from two other published field trials to form an individual patient data meta-analysis (IPDMA).

The ability to predict the effect of anthelmintic treatment on milk production depends on the level of parasitism quantified by an ELISA measuring milk antibodies against Ostertagia ostertagi, and reported as optical density ratios (ODRs). Therefore, the estimates from the interaction between ODR and treatment on milk production were used to determine how well the ODR predicted the response of the treatment. It was anticipated that the relationship between milk production and ODR was unlikely to be linear, so fractional polynomials were applied to the continuous ODR values.

The interaction in the field trial showed a trend $(p=0.138)$ towards a beneficial treatment effect when the individual ODR values, measured in late lactation and using Svanovir®, were greater than 0.12 . When individual data from two other similar studies were included in an IPDMA, the interaction terms became statistically significant $(p=0.009)$ indicating that there is a beneficial treatment effect when ODR values are slightly elevated. A graph was used to demonstrate the treatment effect (the estimated difference of $\mathrm{kg} / \mathrm{cow} / \mathrm{day}$ of milk yield between the treated and placebo cows), with 95\% confidence intervals, as the ODR values increase. It is important to note that the methods of quantifying the ODR values differed between the three studies in the IPDMA, therefore some caution should be used when using these final estimated values. However, the shape and magnitude of the treatment 
effects, as well as the other fixed model estimates, were very similar between the field trial and the IPDMA suggesting that any bias would likely be minimal.

Keywords: Cattle, ELISA, Ostertagia ostertagi, Milk, Individual Patient Data MetaAnalysis, Fractional Polynomial

\section{Introduction}

Gastrointestinal nematodes, such as Ostertagia ostertagi and several species of Cooperia, are ubiquitous in temperate climates (Gibbs, 1988; Williams et al., 1993; Louw, 1999). They have been primarily considered as a production limiting disease in first-season grazing animals, though in the past decade, more evidence has demonstrated their detrimental effects on production in adult dairy cattle. In a recent meta-analysis, Sanchez et al. (2004) demonstrated that overall, producers lose approximately $0.35 \mathrm{~kg}$ of milk per parasitized cow per day. The meta-analysis included 75 studies worldwide with many different drugs, and levels of pasture exposure. The fifteen studies evaluating the use of ivermectin, moxidectin or eprinomectin averaged 301 cows and a beneficial improvement of $0.8 \mathrm{~kg} / \mathrm{cow} / \mathrm{day}$. Of those studies, seven had significant differences with an overall estimated difference of 0.97 $\mathrm{kg} / \mathrm{cow} /$ day.

Diagnostic techniques to identify and/or quantify intestinal parasites have improved over the years. Fecal egg counts have traditionally been utilized to identify and quantify infections, however, this test is plagued with false negatives, high variability between consecutive tests (low repeatability), and overall underestimation of the level of infection (Gross et al., 1999; 
Agneessens et al., 2000; Borgsteede et al., 2000; Eysker and Ploeger, 2000). Serum pepsinogen tests have had some success with quantifying levels of parasitism in first-season grazers, but were less reliable when used to quantify infections in adult cattle (Gross et al., 1999; Agneessens et al., 2000; Borgsteede et al., 2000). Unfortunately, the accuracy of the pepsinogen test depends on the current life cycle stages of the nematodes in the host (Berghen et al., 1993).

The first enzyme-linked immunosorbent assay (ELISA) test to quantify nematode infections in cattle was developed in 1981 (Keus et al.), and since then, many in-house ELISAs have been developed for studies to quantify the infections and their related production losses (Kloosterman et al., 1984; Canals and Gasbarre, 1990; Dohoo et al., 1997; Eysker and Ploeger, 2000; Sanchez et al., 2001; Sithole et al., 2005b). More recently, Svanova (Svanova Veterinary Diagnostics, Uppsala, Sweden) developed a commercial ELISA (Svanovir ${ }^{\circledR}$ ) available in Europe (Charlier et al., 2005a; Guiot et al., 2007; Forbes et al., 2008; Almería et al., 2009). ELISA results are usually normalized, using control samples, and reported as optical density ratios (ODRs) (Sanchez et al., 2002a; Charlier et al., 2005b; Vanderstichel et al., 2010), to reduce between plate variation.

The ELISA has demonstrated some predictive abilities as a tool to estimate the amount of milk production loss due to an unknown level of parasitism at the individual and herd level (see Table 1 for a summary of the studies' estimates, as described in the literature). The best scenario to predict milk loss in cattle due to gastrointestinal parasitism is to test every individual cow in the herd and derive individual milk loss values, as compared to the simpler method of testing one bulk tank milk sample for an entire herd. Only one study (Sanchez et 
al., 2005) was able to statistically demonstrate this predictive ability of the ELISA from individually treated cows and individual cow samples, however, they had targeted confined and semi-confined dairy herds. The objective of this study (field trial) was to use ELISA results from individual cow milk samples to predict milk production response following randomized anthelmintic treatment of individual cows with at least some access to pasture. Specifically, the data collected from this field trial, as well as the data from two other field trials (Sanchez et al., 2002b; Sanchez et al., 2005), were used to calculate the final estimates; all three studies were combined into an individual patient data meta-analysis (IPDMA) to increase statistical power.

\section{Materials and Methods}

\subsection{Herd and Animal Selection for the Field Trial}

Producers in the National Cohort of Dairy Farms (NCDF) study carried out by the Canadian Bovine Mastitis Research Network (CBMRN) (Reyher et al., 2011), a network of farms, laboratories, and researchers investigating mastitis in Canadian herds, were contacted. Herds participating in the NCDF represented typical Canadian commercial dairy farms, based on provincial milk production levels, specified distributions of bulk tank somatic cell count (SCC), and housing types (Reyher et al., 2011). Farms were included in this study if either milking cows, dry cows or heifers had access to pasture or a grassed paddock during the year, to ensure some levels of exposure to infective nematode larvae. Within the NCDF, forty farms allowed their cattle access to pasture or paddock. The target sample size was to include approximately 45 herds with an estimated 3,000 cows; the sample size was determined from simulations based on two previous studies (Sanchez et al., 2002b; Sanchez 
et al., 2005), and accounted for clustering effects from the herds. Specifically, the partial correlations for the ODR and treatment terms in the final model from the two studies were 0.07 for Sanchez et al. (2002b), and 0.06 for Sanchez et al. (2005). A simulation using a hypothetical dataset with two variables correlated at $\mathrm{r}=0.07$ was generated. Random samples of 1,000 cows were obtained and the $5^{\text {th }}$ and $95^{\text {th }}$ percentile of the regression coefficient were obtained - this process was repeated ten times, and the results were averaged. The entire process was repeated for random samples of 2,000,3,000, and 4,000 cows. The simulation determined that 2,000 cows would provide adequate estimates to find a significant treatment effect, however, 3,000 cows would increase the precision of the estimate and account for likely subject drop-outs.

\subsection{Sampling and Milk Collection for the Field Trial}

The procurement of on-farm milk samples, for the ELISA to measure $O$. ostertagi antibodies, came from both CBMRN and routine Dairy Herd Improvement (DHI) milk collections, between March 1, 2007 and April 30, 2008. DHI programs provide producers monthly records of milk production, milk quality, and reproduction parameters. Milk samples were either frozen $\left(-20^{\circ} \mathrm{C}\right)$ or refrigerated $\left(2\right.$ to $\left.4^{\circ} \mathrm{C}\right)$. A previous study found that milk handling procedures, necessary for transportation, storage, and DHI testing, did not have any impact on ELISA results (Vanderstichel et al., 2010). Samples were identified and barcoded by either the CBMRN or the DHI companies - Valacta (formerly ADLIC in the Maritimes) and CanWest. When necessary, the milk samples were matched with their corresponding cow and collection date from the Canadian DHI database, Vision2000.

The individual milk production records were accessed directly from the Canadian DHI 
database and were used to measure the outcome of interest, namely the amount of milk produced (in $\mathrm{kg} / \mathrm{cow} /$ day) on the testing day. The milk production records also contained the testing date, days in milk, calving date, lactation number, and somatic cell counts (SCCs) for each cow.

\subsection{Measuring Parasitism (ELISA) in the Field Trial}

Milk collected from cows during their late lactation period ( $>200$ days in milk) were processed to quantify $O$. ostertagi antibodies using a commercial ELISA kit, Svanovir ${ }^{\circledR}$, and were tested according to the manufacturer's specifications. Samples were tested once as recommended by Sanchez et al. (2002a), however, positive, negative and blank controls were run in triplicates for each plate - both positive and negative controls were supplied. The spectrophotometer (SpectraMax) and software (SoftMax) were programmed following the manufacturer's recommendations. Optical densities (ODs) were exported into electronic text files, matched with their corresponding barcodes, and finally merged with their respective cow data. All ODs within ELISA plates were normalized, producing optical density ratios (ODRs), using the mean from the triplicate positive and negative controls from their respective plate. This commonly used normalization method reduces plate-to-plate variation, and relates values from samples to their standardized controls (Sanchez et al., 2002a; Charlier et al., 2005b; Vanderstichel et al., 2010):

$$
O D R=\frac{\left(O D_{\text {sample }}-O D_{\text {negative }}\right)}{\left(O D_{\text {positive }}-O D_{\text {negative }}\right)}
$$

\subsection{Field Trial Treatment}

All cows calving between May 1, 2007 and May 31, 2008 received one dose of either 
eprinomectin $\left(\right.$ Eprinex $\left.^{\circledR}, 65 \mathrm{ml}=325 \mathrm{mg}\right)$ or mineral oil $(65 \mathrm{ml}$, acting as placebo $)$ applied along the backline from the withers to the tail head, near the time of parturition ( 2 weeks preto 3 days post-parturition). The amount of eprinomectin administered was based on the manufacturer's recommended dose for an average dairy cow weighing $650 \mathrm{~kg}$, which was considered safe and efficacious for the study population (Shoop et al., 1996). Each bottle was numbered and the treatment allocation was randomized using systematic randomization to assign odd or even bottle numbers to a treatment group. Producers administered the treatments sequentially, unaware of the contents within the bottle, and recorded the bottle number, cow identification, and calving date. This information was later merged with the production records and respective ELISA results. Producers were asked, when possible, to keep treated cows apart for as long as they could after treatment (ideally more than 24 hours); there is evidence that macrocyclic lactones (such as ivermectin, doramectin, moxidectin, and eprinomectin) can be transferred mechanically from cow-to-cow via grooming and licking (Laffont et al., 2001; Barber and Alvinerie, 2003). Specifically, Barber and Alvinerie (2003) described mechanical transfer in all treatment groups in their study, including eprinomectin treated cattle. It is worth noting that Alvinerie et al. (1999) found systemic absorption, as measured by the half-life of absorption ( $t_{1 / 2} \mathrm{ka}$ ) for eprinomectin to be twice as fast than what is documented in literature for ivermectin and doramectin. Although mechanical transfer is possible for eprinomectin, it is likely to be less than what would be expected for other macrocyclic lactones because of the faster absorption, however, there are no published studies describing this specific difference.

Only the primary investigators involved had knowledge of the randomization protocol. 


\subsection{Field Trial Questionnaire}

All participating dairy producers completed a 'parasite' questionnaire about anti-parasitic

treatments (before and during the study), pasturing techniques, housing of milking cows, dry cows and heifers, and the length of time treated cows were kept apart after treatment (see Appendix A). This questionnaire was part of a larger questionnaire (CBMRN questionnaire) for all herds within the NCDF. One question included in the parasite questionnaire was used as a validation tool for the CBMRN questionnaire, as described by Dufour et al. (2010); the questions in each questionnaire were posed, on average, 262 days (SD 75) apart. These validation results from the CBMRN questionnaire also reflect the validity of the parasite questionnaire.

Heifers and cows in the field trial were categorized according to their treatment status, and their completeness of information for ELISA results. A flow chart was created to summarize their status within the field trial and subsequently for the analysis (Fig. 1).

\subsection{Including Other Studies for the Individual Patient Data Meta-Analysis}

Traditionally, the term meta-analysis is used to describe methods to synthesize aggregated study-level data. However, meta-analysis of individual patient data, using individual-level data, is gaining popularity in human studies and offers statistical advantages over metaanalyses of study-level aggregate data (Riley et al., 2010) - these meta-analyses of individual-level data are commonly referred to as individual patient (or participant) data meta-analysis (IPDMA). For our objective, combining data from other studies with similar study designs was going to increase statistical power and better predict the amount of milk 
loss ( $\mathrm{kg} / \mathrm{cow} /$ day) from an ELISA result taken from an individual cow. The IPDMA inclusion criteria, for additional field trials, were that individual cows received a treatment (anthelmintic or placebo), milk samples were collected from individual cows to determine ODR values, and milk production records were kept for individual cows. From Table 1, only two studies fit these criteria (Sanchez et al., 2002b; Sanchez et al., 2005), both of which were conducted in Canada and had available datasets.

\subsection{Statistical Analyses}

Unless otherwise stated, all statistical analyses, including summary and descriptive statistics, were performed in Stata 11 (2009).

\subsubsection{Multivariable Mixed Analysis}

\subsubsection{Repeated Measures and Random Effects}

Statistical models, for the field trial, included only those cows for which all information was collected (Groups F and I in Fig. 1), which included a late-lactation milk sample with an ELISA result, a properly recorded treatment event at calving (placebo or anthelmintic), and at least one milk production record for the new lactation period.

A multilevel mixed-effects linear regression, with test day milk yield $(\mathrm{kg} / \mathrm{cow} / \mathrm{day})$ as the dependent variable, was fit using maximum likelihood estimation (Stata 11, xtmixed), with first order auto-regressive (AR1) structured residual errors between repeated milk measurements; the same residual error structure for the field trial was applied to the IPDMA model and was the best choice in both studies by Sanchez et al. (2002b; 2005). There were 
two random effect variables (herd and cow), and a residual structure between DHI test dates, creating a 3-level hierarchy to the analysis - herds, cows, and test dates (repeated cow milk yields within lactations).

\subsubsection{Fixed Effects}

The variable for time period and seasonal effects was divided into periods of 4 months (thrice-yearly periods) throughout the field trial period ('Housed' $=$ January $15^{\text {th }}$ to May $14^{\text {th }}$; 'Grazed' $=$ May $15^{\text {th }}$ to September $14^{\text {th }}$, and 'Shoulder' $=$ September $15^{\text {th }}$ to January $\left.14^{\text {th }}\right)$, starting May 1, 2007 and ending December 31, 2008, giving a total of 5 thrice-yearly periods. The dates used to define the periods (Housed, Grazed, and Shoulder) were based on grazing seasons in Canada, where cows are typically turned out to pasture in the middle of May and the first frost usually occurs after the middle of September; the 'shoulder' period is a transitional period between fully grazed and fully housed. Cow-level variables included both calving season (three categories, using the same thrice-yearly periods as the seasonal effects), and lactation number (separated into three categories; $2^{\text {nd }}, 3^{\text {rd }}$, and $\geq 4^{\text {th }}$ lactations). Variables related to testing dates and affecting milk yields were milk somatic cell counts, and days-inmilk (DIM). SCCs were transformed to a natural logarithm scale (lnSCC) to linearize their effect (Dohoo et al., 2009). The relationship between DIM and milk yield was assumed to follow Wilmink's function (Schaeffer et al., 2000): $\mathrm{Y}=\mathrm{DIM}+\mathrm{DIM}^{-0.05}$, where $\mathrm{Y}$ is the 24-hour milk yield in $\mathrm{kg} / \mathrm{cow} / \mathrm{day}$; the first DIM term was centered to reduce collinearity between the two terms, and the second DIM was computed from the original DIM variable.

All three datasets in the IPDMA contained many of the same variables (age, treatment group, ODR value, calving date, milk sampling date, milk production [kg/cow/day], DIM, and 
somatic cell count), except for those variables in the field trial that were derived from the questionnaire. In brief, the fixed 'season' variable was allowed to span between years within studies, and between studies, which meant that this variable accounted for the differences in milk production due to the varying seasons, years and studies; this variable was expanded to include 14 thrice-yearly periods starting September $15^{\text {th }}, 1999$ and ending January $14^{\text {th }}, 2008$.

The fundamental differences between the field trial model and the IPDMA model were the number of seasonal categories that were allowed to span over different time periods (respective of their study periods) and the inclusion of one questionnaire variable that was related to the farm's previous use of anthelmintics (data were available for the field trial, but not for the IPDMA).

\subsubsection{Fractional Polynomial and Treatment Effects}

The treatment effect of eprinomectin was expected to depend on the level of parasitism in the cow, where low ODR values indicated low levels of parasitism (Ploeger et al., 1989; Kloosterman et al., 1993). Therefore, the estimates from the interaction between ODR and treatment on milk production were used to determine how well the ODR predicted the response to treatment. The relationship between milk production and ODR is unlikely to be linear (Sanchez et al., 2005), so fractional polynomials were applied to the continuous ODR values.

A 2-degree fractional polynomial (FP), using two terms, is likely the most parsimonious method to obtain a good fit to the data (Royston and Sauerbrei, 2008). The FP analysis (fracpoly, Stata 11) generated two new centered terms, the first being the variable to the power of a calculated constant (one of the following: $-3,-2,-1,-0.5,0,0.5,1,2$, and 3 , where 
0 refers to a natural logarithm transformation) and the second being either a second power term from the same series or the product of the natural log of the variable and the variable raised to the same power. For example, ODR could be modeled by $\mathrm{ODR}^{\mathrm{p} 1}$ and $\mathrm{ODR}^{\mathrm{p} 2}$, where if the power selected to produce the best-fit for both terms is $-2, \mathrm{ODR}^{\mathrm{p} 1}=\mathrm{ODR}^{-2}$, and $\mathrm{ODR}^{\mathrm{p} 2}=\mathrm{ODR}^{-2} \ln (\mathrm{ODR})$. Royston and Sauerbrei (2008) recommend to test a binary-bycontinuous interaction, when the continuous term is transformed into a fractional polynomial, with a likelihood ratio test between the nested model and the full model using maximum likelihood (ML) methods (not restricted-ML methods). The difference in deviance is compared with a $\chi^{2}$ distribution on two degrees of freedom. In this study, the FP analysis of ODR generated two new terms $\left(\mathrm{ODR}^{\mathrm{p} 1}\right.$ and $\left.\mathrm{ODR}^{\mathrm{p} 2}\right)$; four new variables were subsequently generated, two FP terms for each eprinomectin and placebo groups, giving: $\mathrm{ODR}_{\mathrm{tx}=0}{ }^{\mathrm{p} 1}$, $\mathrm{ODR}_{\mathrm{tx}=0}{ }^{\mathrm{p} 2}, \mathrm{ODR}_{\mathrm{tx}=1}^{\mathrm{p} 1}, \mathrm{ODR}_{\mathrm{tx}=1}{ }^{\mathrm{p} 2}$. If $\mathrm{x}^{*}$ represents all other fixed explanatory variables, the

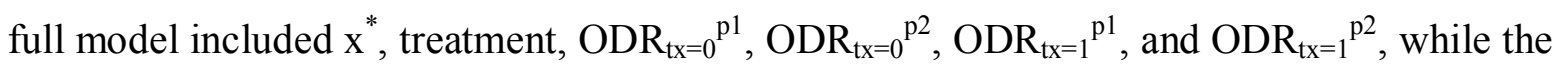
reduced model included $\mathrm{x}^{*}$, treatment, $\mathrm{ODR}^{\mathrm{p} 1}$, and $\mathrm{ODR}^{\mathrm{p} 2}$. The overall treatment effect was derived by subtracting the estimates of $\mathrm{ODR}_{\mathrm{tx}=0}{ }^{\mathrm{p} 1}$, and $\mathrm{ODR}_{\mathrm{tx}=0}{ }^{\mathrm{p} 2}$ from $\mathrm{ODR}_{\mathrm{tx}=1}^{\mathrm{p} 1}, \mathrm{ODR}_{\mathrm{tx}=1}^{\mathrm{p} 2}$, and treatment. The treatment effect and its confidence interval were plotted against ODR to visualize the relationship between ODR and treatment effect.

Best linear unbiased predictions (BLUPs) were calculated for both random effects (herds and cows) to verify the assumptions of heteroscedasticity. The standardized residuals from the repeated measures were plotted against the predicted outcome. Normality and heteroscedasticity of residuals, at all levels of the model, were evaluated. (Dohoo et al., 2009) 
Reporting of the field trial followed the REFLECT statement (Reporting Guidelines For Randomized Control Trials) (O'Connor et al., 2010) as closely as possible.

\section{Results}

\subsection{Herd and Animal Selection for the Field Trial}

There were 98 herds in the NCDF and of those 40 herds met the selection criteria and agreed to participate in the field trial. Two herds failed to record cow treatments and were removed, leaving a total of 38 herds across Canada. Specifically, herds came from the provinces of Alberta (5), Ontario (6), Québec (11), New Brunswick (5), Nova Scotia (4), and Prince Edward Island (7).

Figure 1 shows the final allocation of cows and heifers into their groups based on treatment and data completeness. There were on average 35 cows (range 6 to 80 ) from each herd that contributed to the field trial.

\subsection{Sampling and Milk Collection for the Field Trial}

Overall, there was an average of 9.0 DHI milk tests per cow (median=9, $S D=2.6$, range $=1$ 17). DHI programmes schedule approximately 10 visits per year, and the average time period between visits for all cows in the field trial was 34 days $(S D=5.72)$. The test period number was defined sequentially from when the cow started her lactation, and any missing visits were marked as such, leaving a gap in the order sequence; there were 119 missing tests from the total of 10,333 recorded.

The average 24-hour milk yield for all cows from all test dates was $32.2 \mathrm{~kg} / \mathrm{cow} / \mathrm{day}$ 
(median=31.6, $S D=9.5$ ), and average days in milk for all test dates was 157.8 (median=149, $S D=99.2)$

\subsection{ELISA and Milk Production in the Field Trial}

There was on average, 2.2 individual ODR samples per tested cow-lactation (range 1 to 9). ODR values from late lactation periods were recorded as the latest ODR value for that cow, regardless of the sample date. The median day between the test date and the calving date for the latest ODR values was 88 (IQR 68 to 133). The overall average latest ODR value for all cows with ODR values (Groups F, I, and L, Fig. 1) was 0.307.

\subsection{Field Trial Treatment}

A total of 2,117 treatments (either placebo or anthelmintic) were dispensed, with 2,058 doses applied during the correct time interval ( 2 weeks pre- to 3 days post-parturition). The placebo group (Fig. 1, Group I) had an averaged latest ODR value of 0.303 (IQR 0.111 to 0.448) while the eprinomectin group (Fig. 1, Group F) had 0.297 (IQR 0.098 to 0.427). There were no reported adverse reactions to any of the treatments.

\subsection{Field Trial Questionnaire}

Between May 2006 and April 2007, prior to the commencement of the study, 73\% (27/37) of the producers in the study had used medications for deworming and/or external parasite control within the past 12 months. Eighty six percent of the producers who used antiparasitic drugs, treated their milking cows. Treating milking cows prior to calving was the most popular period to treat $(11 / 28=39 \%)$, followed by treating all milking cows in the Fall $(10 / 28=36 \%)$. Again, those producers who used anti-parasitic drugs, $75 \%$ treated their 
heifers. Fall treatment of heifers was the most popular $(12 / 28=43 \%)$, followed by spring treatment of heifers $(9 / 28=32 \%)$. During the summer of 2007 , approximately half $(54 \%)$ of the producers in the study had their milking cows on pasture, while the other half kept them confined. The vast majority of producers placed their dry cows on pasture $(27 / 38=71 \%)$, and a similar number of producers also kept their heifers on pasture $(26 / 38=68 \%)$. Half $(15 / 30=50 \%)$ of those who did place either milking cows, dry cows or heifer on pasture, kept them within their respective groups (i.e. dry cows with dry cows only), while $37 \%$ mixed their dry cows with their heifers on the same pastures.

During the field trial, 21 herds could not keep their cows apart after treatment, while only 4 herds were able to keep them apart for more than 24 hours (recommended); the remaining 12 herds varied between one and 24 hours.

\subsection{Combined dataset for the Individual Patient Data Meta-Analysis}

After appending the data from the two similar Canadian studies (Sanchez et al., 2002b; Sanchez et al., 2005) to the field trial dataset, there were 87 herds, 2,018 cows with 12,524 milk samples. Table 2 summarizes the data contributions from Sanchez et al. (2002b) and Sanchez et al. (2005) for the IPDMA.

\subsection{Multivariable Mixed Analysis}

\subsubsection{Repeated Measures}

The AR1 correlation structure, and its correlation values over time, was similar to the unstructured matrix and had been the preferred residual structure in both studies by Sanchez et al. (2002b; 2005). Therefore, AR1 was the chosen residual structure for the remaining 
models for both the field trial and the IPDMA. For the models to converge, the number of repeated milk yields per cow lactation was truncated to 10 values over time, which was deemed biologically adequate to assess the treatment effect.

\subsubsection{Random Effects in the Models}

There were two random variables included in the final field trial model (Table 3) and the final IPDMA model (Table 4) - a herd and cow variable. The estimated correlations between test periods, derived from the AR1 residual structure, ranged from 0.429 to 0.693 for the field trial, and from 0.493 to 0.717 for the IPDMA. Specifically, the first four correlations between $1,2,3$, and 4 test periods apart were $0.693,0.550,0.485$, and 0.455 , respectively, for the field trial, and $0.717,0.592,0.537$, and 0.512 , respectively, for the IPDMA.

\subsubsection{Fixed Effects}

All of the fixed effects selected for their biological merits to explain milk yields, were statistically significant at $p=0.05$ (or nearly so) in the models for the field trial and the IPDMA; their estimates are shown in Tables 3 and 4, respectively.

\subsubsection{Fractional Polynomial and Treatment Effects}

Both models had FP terms for the ODR values and included two centered FP terms for the latest ODR values. The terms for the field trial were: $\mathrm{ODR}^{\mathrm{p} 1}=\left(\mathrm{ODR}^{-2}\right)-0.5775$ and $\mathrm{ODR}^{\mathrm{p} 2}=\left(\mathrm{ODR}^{-2} \mathrm{x} \ln (\mathrm{ODR})\right)-0.1585$, while the terms for the IPDMA were: $\mathrm{ODR}^{\mathrm{p} 1}=\left(\mathrm{ODR}^{-2}\right)-$ 0.5754 and $\mathrm{ODR}^{\mathrm{p} 2}=\left(\mathrm{ODR}^{-2} \mathrm{x} \ln (\mathrm{ODR})\right)-0.1590$. The maximum log likelihood for the field trial model with the main effects for ODR was -25594.08 , while it was -25592.10 for the field trial model with all four FP terms for the treatment by ODR interaction; the $\chi^{2}$ statistic 
from the likelihood ratio test was 3.96 for two degrees of freedom, giving a non-significant $p$-value of 0.138 for the interaction. Conversely, the $\chi^{2}$ statistic from the likelihood ratio test between the IPDMA model with the main effects for ODR and the IPDMA model with all four FP terms for the treatment by ODR interaction was 9.38, giving a statistically significant $p$-value of 0.009 for the interaction.

Figure 2 shows the interaction plot for ODR values from both the placebo and treated cows, against normalized milk production values, for the field trial (A) and the IPDMA(B), where zero on the $y$-axis represents the average placebo cow production ( $\mathrm{kg} / \mathrm{cow} / \mathrm{day})$ when all other predictors in the model are held constant. The interaction plot illustrates how milk production is influenced by ODR values, while the effect of treatment, as shown in Fig. 3, is derived from the differences in milk yields between placebo and treated cows. For the field trial (Fig. 3A), the estimated treatment effects were positive when ODR values were above 0.12 , however, the lower bound of the $95 \%$ CI never went above zero. The maximum estimated treatment effect occurred when ODR was equal to 0.46 , where it was estimated to increase milk production by $0.73 \mathrm{~kg} / \mathrm{cow} /$ day. There was a negative effect of treatment when ODR values were below 0.12 , though the confidence interval was relatively large for these values. The confidence interval range also rose quickly as ODR values increased above 0.6. The decline in the difference between treatment and placebo for ODR values above 0.6 is due to the apparent decline in production in treated cows above this ODR level. There are relatively few observations with ODR values greater than 0.6 in the treated cows (593 out of 4096 observations from treated cows $=14.48 \%$ ). The graph for the IPDMA (Fig. 3B) was similar to the field trial graph, with a few differences, mainly that the treatment effects were positive when ODR values were above 0.18 , the maximum estimated treatment effect was 
$0.67 \mathrm{~kg}$ milk/cow/day when the ODR value is 0.57 , and the lower bound of the confidence interval is greater than zero when the ODR values are between 0.43 and 0.53 .

\subsubsection{Model Diagnostics}

There was no visual indication of any model assumption violations for both the field trial and IPDMA models, and no transformations of the outcomes were deemed necessary.

\section{Discussion}

Based on the sampling design used to select the NCDF producers, herds available to this field trial study represented the current distribution of commercial dairy farms in Canada. Herd selection was founded on milk production, bulk tank somatic cell counts, and housing type. CBMRN recorded that $34 \%$ of the NCDF farms were housed in 'freestall', which was comparable to estimated national (region-weighted) averages of 36\% (Reyher et al., 2011). It is possible that housing types of study herds do not accurately reflect farm pasturing protocols, however, it is likely these farms represented the average pasture exposure of dairy cattle across Canada. Only those farms which allowed cattle to have access to pasture or paddock at some time during their production cycle were included in this study, thus representing a subset population of the typical Canadian dairy farms.

The pasturing method inclusion criteria were deemed important to ensure a certain level of exposure of infective nematode larvae to increase the statistical power of the study. Variables describing the producer's pasturing techniques were derived from the parasite questionnaire. Treatment effects were expected to vary according to the pasturing techniques, though no significant or interesting relationships were observed during the analysis. 
The average ODR value in this study was lower than anticipated (0.26, SD 0.24), despite the inclusion criteria, when it was compared to other reported studies from similar regions. Sithole et al. (2005a) reported an average herd bulk tank ODR of 0.41 (SD 0.13) for 65 herds with limited outdoor exposure during a one year period, however, bulk tank ODR values are usually higher than averaged individual ODRs (Charlier et al., 2010). Sanchez et al. (2002b), had similar, though slightly higher, results from individual ODRs; the recorded average was 0.23 (SD 0.25) with a larger range from -0.05 to 1.56 . Later, in 2005, Sanchez et al. (2005) reported a lower median ODR value of 0.23 (IQR 0.10-0.42) for confined cows, and it was expected that those cows without pasture access were going to yield smaller ODR values.

When looking at the ODR value determined for the individual cow (summary value for the late lactation period), the ODR values were very similar between the field trial and Sanchez et al. (2005), as presented in Table 2, but different from Sanchez et al. (2002b). It is worth noting that Sanchez et al. (2002b) and Sanchez et al. (2005) used in-house ELISA kits with different controls than those used by Svanova, which would influence their ODR values, and could also account for different ODR values between studies. It is also possible that over time (since 1999) more producers were using anthelmintics on their farm prior to the subsequent field trials which could reduce the overall worm burden on the farms.

The AR1 residual structure was assumed to be present for up to and including ten test dates; all the information for an expected lactation period (10 months) could be computed for both the field trial and the IPDMA models. In the field trial model, as test dates got further apart, the milk yield correlations between the test dates decreased, however, after the $6^{\text {th }}$ test, there 
were very little differences and the correlations stayed very close to the constant 0.43 ; this relatively elevated constant correlation indicates a moderate amount of clustering within a cow, no matter when the milk was taken. Similarly, in the IPDMA, the milk yield correlations changed very little after the $6^{\text {th }}$ test and remained near the constant 0.49 .

The interaction in the field trial, explaining the treatment effect, was not statistically significant $(p=0.138)$, and there were three potential contributing factors. (1) Many of the herds with 'access' to pasture had limited access, such as a paddock, or only allowed a group of animals (e.g. dry cows or heifers) to graze. This limited access to pasture would have reduced the exposure of cows to the parasite's infective stage, reflected in low ODR values. (2) Three quarters of the herds had been using an anthelmintic on the farm within one year of the study. Therefore anthelmintic treatment before the study (and throughout the study), may have reduced the overall parasite exposure on the farm. It is therefore more difficult to investigate the interaction if there were few larger ODR values (Bailar and Mosteller, 1988). (3) Although the producers were asked to keep their cows apart for at least 24 hours after treatment, only four farms managed to do so. It is difficult to estimate the importance of mechanical transfer of eprinomectin treated cattle between animals. However, some amount of mechanical transfer is plausible. Each of those three factors could have individually biased the interaction term towards the null hypothesis. Furthermore, interaction terms require additional statistical power to be detected when compared to the ability to detect main effects (Greenland, 1993).

There are important differences between the three studies which could influence the interpretation from the IPDMA. While the ODRs were all determined in a similar fashion, 
the time intervals to include ODR values during the previous late lactation period for cows did vary between studies. Sanchez et al. (2002b) averaged the ODRs within 90 days of calving; if ODRs were not available before 90 days, then the ODRs from the last 120 days were accepted. Sanchez et al. (2005) were less strict and included all ODRs within 150 days from calving (approximately the last 3 months in lactation). Only the latest ODR value was included in the field trial study, and milk samples were collected after 200 DIM from the previous lactation; the median day between the test date and the calving date for the latest ODR values was 88 days (IQR 68 to 133). The studies also had different control samples, where both Sanchez et al. (2002b) and Sanchez et al. (2005) used in-house sample controls, while the field trial used Svanova's sample controls. Since ODRs depend on the controls, it is possible that different controls could influence ODR values.

Fractional polynomials can be used to model a wide range of shapes of relationships with only a few (often two) variables, therefore, offer good fit to the data while being parsimonious. In general, FPs are more flexible than conventional polynomials, and remain somewhat resistant to local-influences, making them suitable for predictions. They are, however, more sensitive to extreme values at either end of the distribution, and they are reported to have a reduced power to detect non-linear functions (Royston and Sauerbrei, 2008). Therefore, caution should be used when interpreting estimates from either end of a FP distribution and where there are fewer observations in the data.

The statistical significance of the interaction is derived from the differences in the FP slopes for the placebo and the treated cows, or from the non-zero slope of the treatment effect, as seen in Fig. 3B. The significant interaction comes from the curvature in the slope between 
ODR values of 0.07 and 0.48 , as seen by the $95 \% \mathrm{CI}$ in Fig.3B. Between the ODR values of 0.07 and 0.17 , the model predicts a negative effect from treatment, as low as $0.67 \mathrm{~kg} / \mathrm{cow} / \mathrm{day}$. This negative treatment effect for low ODR values, although difficult to biologically explain, was observed by Sanchez et al. (2005) with a quadratic term in the model - this being the only other study with continuous ODR values (Table 1) to have assumed a non-linear relationship between ODR and milk production. It is possible that there is a real negative milk production effect for low ODR values which was not detected in other studies because of their chosen methods to model the relationship between ODR values and milk production. It is also possible that this estimated effect is exaggerated by the FP's sensitivity to extreme ODR values at either ends of the treatment effect curve, and due to a relatively small number of observations; for example, fewer than $14 \%$ of the observations in the IPDMA had ODR values below 0.05 .

The estimated treatment effect for the field trial peaked at $0.73 \mathrm{~kg}$ milk/cow $/$ day when the latest ODR value was 0.46 , and for the IPDMA it peaked at $0.67 \mathrm{~kg}$ milk/cow $/$ day when the latest ODR value was 0.57 ; this positive treatment effect continuously declined after the ODR value of 0.46 in the field trial and 0.57 in the IPDMA, though it always remained positive. There were few data points for the estimation of the milk production $(\mathrm{kg}$ milk/cow/day) when ODR values were greater than $0.6(<15 \%$ of those modeled values for both models), as such the reader should not necessarily trust the downward trend in milk production for higher ODR values. Ploeger et al. (1989) had an estimated treatment effect at the upper antibody level range of approximately $1.5 \mathrm{~kg}$ milk/cow/day (estimated from both the graph and regression coefficients, converted from standardized 305 day production). Charlier et al. (2010) ran several statistical models, and the final model (including all 
parameters and the interaction) estimated the treatment effect to be $>3.58 \mathrm{~kg}$ milk/cow/day when ODR was greater than 1 .

When comparing these results (field trial and IPDMA) with those from the two studies included in the IPDMA, the FP terms for the ODR plotted against milk production for both the field trial and the IPDMA (Fig. 3 A and B) appeared very similar to the quadratic terms Sanchez et al. (2005) found when looking at individual cow ODR values from confined or semi-confined Canadian dairy herds; they found a greater treatment effect at the upper ODR range. Sanchez et al. (2002b) investigated individual ODR dichotomized (high/low, 0.5 cutpoint) and estimated the interaction effect to be $2.99 \mathrm{~kg}$ milk/cow/day - the remaining studies investigated bulk tank milk samples. The studies evaluating the treatment effects on milk production as individual anti-parasite antibodies increase (serum or milk on a continuous scale) found consistent positive results, although there has been variation in the estimated magnitude of the response.

The graph in Fig. 3B can be used as a guide to interpret Svanovir ${ }^{\circledR}$ ELISA results, from individual dairy cow milk samples, to estimate the amount of milk loss ( $\mathrm{kg} / \mathrm{cow} / \mathrm{day})$ that is associated with the level of parasitism. Based on this graph (Fig. 3B), on average, anthelmintic treatment will probably improve a cow's milk production if the individual cow ODR value is approximately 0.2 or greater, and treating a cow with an ODR value greater than 0.4 will very likely improve its milk production. Economic considerations will dictate if veterinarians and producers should test and treat individual cows, based on the costs of the test and treatment, and the estimated amount of milk loss from the graph (Fig. 3B). Future studies to develop guidelines for the use of bulk tank milk samples and herd-level treatment 
protocols will improve the feasibility of this ELISA as a routine diagnostic tool. However, given that an IPDMA, combining three studies, was necessary to detect a significant interaction effect for individual cows, sufficient sample sizes for statistical power at the herdlevel will likely be a limiting factor for these herd-level studies.

\section{Conclusion}

The ability to predict the effect of anthelmintic treatment on milk production depends on the level of parasitism quantified by an ELISA measuring milk antibodies against Ostertagia ostertagi. The interaction in the field trial showed a trend $(p=0.138)$ towards a beneficial treatment effect when the individual ODR values, using Svanovir ${ }^{\circledR}$ and measured in late lactation, were greater than 0.12 . When individual cow data from two other similar studies were included in an IPDMA, the interaction terms became statistically significant $(p=0.009)$ indicating that there is a beneficial treatment effect when ODR values are slightly elevated.

The three studies in the IPDMA were performed in Canada, and the methods of quantifying the ODR values were different between the studies. Therefore some caution should be used when interpreting and using these estimated values, however, the shape and magnitude of the treatment effects, as well as the other model estimates, were very similar between the field trial and the IPDMA suggesting that any bias would likely be minimal.

\section{Acknowledgements}

The authors would like to thank Judy Sheppard, Doris Poole, and Natasha Robinson for their technical support in the laboratory, the summer veterinary students (with a special thank-you to Anthony Snyder) for their logistical support with handling samples, the members of the 
Canadian Bovine Mastitis Research Network, in particular, Dr Kristen Reyher and the technicians involved with farm visits and sample collections (Theresa Andrews, François Dubois, Mike MacLean, and Anke Wellen), and to Françoise Tétrault for the translation of all written communications for francophone producers, including the questionnaire. This study was funded by Merial Canada Inc., the Dairy Farmers of Canada, Maritime Quality Milk, the Natural Sciences and Engineering Research Council of Canada, and the ELISA kits were provided by an in-kind contribution from Svanova Biotech AB.

\section{Conflict of Interest}

There were no known conflicts of interest.

\section{References}

Agneessens, J., Claerebout, E., Dorny, P., Borgsteede, F.H., Vercruysse, J., 2000. Nematode parasitism in adult dairy cows in Belgium. Vet Parasitol 90, 83-92.

Almería, S., Adelantado, C., Charlier, J., Claerebout, E., Bach, A., 2009. Ostertagia ostertagi antibodies in milk samples: relationships with herd management and milk production parameters in two Mediterranean production systems of Spain. Res Vet Sci 87, 416420.

Alvinerie, M., Sutra, J.F., Galtier, P., Mage, C., 1999. Pharmacokinetics of eprinomectin in plasma and milk following topical administration to lactating dairy cattle. Res Vet Sci $67,229-232$.

Bailar, J.C., 3rd, Mosteller, F., 1988. Guidelines for statistical reporting in articles for medical journals. Amplifications and explanations. Ann Intern Med 108, 266-273.

Barber, S., Alvinerie, M., 2003. Comment on "A comparison of persistent anthelmintic efficacy of topical formulations of doramectin, eprinomectin, ivermectin and 
moxidectin against naturally acquired nematode infections of beef calves" and problems associated with mechanical transfer (licking) of endectocides in cattle. Vet Parasitol 112, 255-257.

Berghen, P., Hilderson, H., Vercruysse, J., Dorny, P., 1993. Evaluation of pepsinogen, gastrin and antibody response in diagnosing ostertagiasis. Vet Parasitol 46, 175-195.

Borgsteede, F.H., Tibben, J., Cornelissen, J.B., Agneessens, J., Gaasenbeek, C.P., 2000. Nematode parasites of adult dairy cattle in the Netherlands. Vet Parasitol 89, 287296.

Canals, A., Gasbarre, L.C., 1990. Ostertagia ostertagi: isolation and partial characterization of somatic and metabolic antigens. Int J Parasitol 20, 1047-1054.

Charlier, J., Claerebout, E., Duchateau, L., Vercruysse, J., 2005a. A survey to determine relationships between bulk tank milk antibodies against Ostertagia ostertagi and milk production parameters. Vet Parasitol 129, 67-75.

Charlier, J., Duchateau, L., Claerebout, E., Vercruysse, J., 2005b. Assessment of the repeatability of a milk Ostertagia ostertagi ELISA and effects of sample preparation. Prev Vet Med 68, 277-288.

Charlier, J., Vercruysse, J., Smith, J., Vanderstichel, R., Stryhn, H., Claerebout, E., Dohoo, I., 2010. Evaluation of anti-Ostertagia ostertagi antibodies in individual milk samples as decision parameter for selective anthelmintic treatment in dairy cows. Prev Vet Med 93, 147-152.

Dohoo, I., Caldwell, V., Markham, F., Conboy, G., Bouchard, E., DesCôteaux, L., 1997. Evaluation of an ELISA for monitoring parasite burdens in dairy herds. Epidemiologie et Sante Animale, 12.05.11-12.05.13.

Dohoo, I., Martin, W., Stryhn, H., 2009. Veterinary Epidemiologic Research. AVC Incorporated Charlottetown, Canada. 
Dufour, S., Barkema, H.W., DesCôteaux, L., DeVries, T.J., Dohoo, I.R., Reyher, K., Roy, J.P., Scholl, D.T., 2010. Development and validation of a bilingual questionnaire for measuring udder health related management practices on dairy farms. Prev Vet Med $95,74-85$.

Eysker, M., Ploeger, H.W., 2000. Value of present diagnostic methods for gastrointestinal nematode infections in ruminants. Parasitology 120 Suppl, S109-119.

Forbes, A.B., Vercruysse, J., Charlier, J., 2008. A survey of the exposure to Ostertagia ostertagi in dairy cow herds in Europe through the measurement of antibodies in milk samples from the bulk tank. Vet Parasitol 157, 100-107.

Gibbs, H.C., 1988. The epidemiology of bovine ostertagiasis in the north temperate regions of North America. Vet Parasitol 27, 39-47.

Greenland, S., 1993. Basic problems in interaction assessment. Environ Health Perspect 101 Suppl 4, 59-66.

Gross, S.J., Ryan, W.G., Ploeger, H.W., 1999. Anthelmintic treatment of dairy cows and its effect on milk production. Vet Rec 144, 581-587.

Guiot, A.L., Charlier, J., Pravieux, J.-J., Courtay, B., Vercruysse, J., 2007. Relation entre la mesure d'anticops anti-Ostertagia sur lait de mélange et les paramètres de production laitière en France. Bulletin des GTV 38, 89-93.

Keus, A., Kloosterman, A., Van Den Brink, R., 1981. Detection of antibodies to Cooperia spp. and Ostertagia spp. in calves with the enzyme linked immunosorbent assay (ELISA). Vet Parasitol 8, 229-236.

Kloosterman, A., Albers, G.A., van den Brink, R., 1984. Negative interactions between Ostertagia ostertagi and Cooperia oncophora in calves. Vet Parasitol 15, 135-150. 
Kloosterman, A., Verhoeff, J., Ploeger, H.W., Lam, T.J., 1993. Antibodies against nematodes in serum, milk and bulk milk samples as possible estimators of infection in dairy cows. Vet Parasitol 47, 267-278.

Laffont, C.M., Alvinerie, M., Bousquet-Mélou, A., Toutain, P.L., 2001. Licking behaviour and environmental contamination arising from pour-on ivermectin for cattle. Int $\mathbf{J}$ Parasitol 31, 1687-1692.

Louw, J.P., 1999. The helminths of ranch calves in the North-eastern Mountain Grassland of South Africa. Onderstepoort J Vet Res 66, 335-338.

O'Connor, A.M., Sargeant, J.M., Gardner, I.A., Dickson, J.S., Torrence, M.E., Dewey, C.E., Dohoo, I.R., Evans, R.B., Gray, J.T., Greiner, M., Keefe, G., Lefebvre, S.L., Morley, P.S., Ramirez, A., Sischo, W., Smith, D.R., Snedeker, K., Sofos, J., Ward, M.P., Wills, R., 2010. The REFLECT statement: methods and processes of creating reporting guidelines for randomized controlled trials for livestock and food safety. Prev Vet Med 93, 11-18.

Ploeger, H.W., Schoenmaker, G.J., Kloosterman, A., Borgsteede, F.H., 1989. Effect of anthelmintic treatment of dairy cattle on milk production related to some parameters estimating nematode infection. Vet Parasitol 34, 239-253.

Reyher, K.K., Dufour, S., Barkema, H.W., Des Coteaux, L., Devries, T.J., Dohoo, I.R., Keefe, G.P., Roy, J.P., Scholl, D.T., 2011. The National Cohort of Dairy Farms-A data collection platform for mastitis research in Canada. J Dairy Sci 94, 1616-1626.

Riley, R.D., Lambert, P.C., Abo-Zaid, G., 2010. Meta-analysis of individual participant data: rationale, conduct, and reporting. BMJ 340, c221.

Royston, P., Sauerbrei, W., 2008. Multivariable Model-building, a pragmatic approach to regression analysis based on fractional polynomials for modelling continuous variables. John Wiley \& Sons Ltd. 
Sanchez, J., Dohoo, I., Carrier, J., DesCôteaux, L., 2004. A meta-analysis of the milkproduction response after anthelmintic treatment in naturally infected adult dairy cows. Prev Vet Med 63, 237-256.

Sanchez, J., Dohoo, I., Leslie, K., Keefe, G., Markham, F., Sithole, F., 2005. The use of an indirect Ostertagia ostertagi ELISA to predict milk production response after anthelmintic treatment in confined and semi-confined dairy herds. Vet Parasitol 130, $115-124$.

Sanchez, J., Dohoo, I., Markham, F., 2001. Comparison of four methods for computing and presenting ELISA test results. In, Society for Veterinary Epidemiology and Preventive Medicine, Leeuwenhorst.

Sanchez, J., Dohoo, I., Markham, F., Leslie, K., Conboy, G., 2002a. Evaluation of the repeatability of a crude adult indirect Ostertagia ostertagi ELISA and methods of expressing test results. Vet Parasitol 109, 75-90.

Sanchez, J., Dohoo, I., Nødtvedt, A., Keefe, G., Markham, F., Leslie, K., DesCôteaux, L., Campbell, J., 2002b. A longitudinal study of gastrointestinal parasites in Canadian dairy farms. The value of an indirect Ostertagia ostertagi ELISA as a monitoring tool. Vet Parasitol 107, 209-226.

Schaeffer, L.R., Jamrozik, J., Kistemaker, G.J., Van Doormaal, B.J., 2000. Experience with a test-day model. J Dairy Sci 83, 1135-1144.

Shoop, W.L., Egerton, J.R., Eary, C.H., Haines, H.W., Michael, B.F., Mrozik, H., Eskola, P., Fisher, M.H., Slayton, L., Ostlind, D.A., Skelly, B.J., Fulton, R.K., Barth, D., Costa, S., Gregory, L.M., Campbell, W.C., Seward, R.L., Turner, M.J., 1996. Eprinomectin: a novel avermectin for use as a topical endectocide for cattle. Int J Parasitol 26, 12371242. 
Sithole, F., Dohoo, I., Leslie, K., DesCôteaux, L., Godden, S., Campbell, J., Stryhn, H., Sanchez, J., 2005a. Effect of eprinomectin treatment at calving on milk production in dairy herds with limited outdoor exposure. J Dairy Sci 88, 929-937.

Sithole, F., Dohoo, I., Markham, F., Sanchez, J., 2005b. Assessing the agreement between Ostertagia ostertagi ELISA tests performed using the crude adult antigen and the adult and larval stage 4 excretory/secretory antigens. Vet Parasitol 134, 147-152.

SoftMax, 2006. Molecular Devices Analytical Technologies, Release Pro 5, Orleans Drive, Sunnyvale, CA, USA.

SpectraMax, 2006. Molecular Devices Analytical Technologies, Model Plus 384, Orleans Drive, Sunnyvale, CA, USA.

Stata, 2009. Stata Statistical Software, Release 11, College Station, TX, USA.

Vanderstichel, R., Dohoo, I., Stryhn, H., 2010. The impact of milk handling procedures on Ostertagia ostertagi antibody ELISA test results. Vet Parasitol 169, 204-208.

Williams, J.C., Knox, J.W., Loyacano, A.F., 1993. Epidemiology of Ostertagia ostertagi in weaner-yearling cattle. Vet Parasitol 46, 313-324. 
Table 1. Studies, found in the literature, evaluating how quantifying anti-parasite antibodies could predict the milk production response to anthelmintic treatments.

\begin{tabular}{|c|c|c|c|c|c|}
\hline $\begin{array}{c}\text { First } \\
\text { Author } \\
\text { (Year) }\end{array}$ & $\begin{array}{c}\text { Anti-parasite } \\
\text { antibody } \\
\text { (Ind. or BT) }\end{array}$ & $\begin{array}{c}\text { Anthelmintic } \\
\text { Treatment }\end{array}$ & $\begin{array}{c}\text { Effect of Tx } \\
\mathrm{kg} / \mathrm{cow} / \mathrm{day}(\mathrm{SE})\end{array}$ & at $\mathrm{Ab}$ value & $P$ value \\
\hline $\begin{array}{l}\text { Charlier } \\
\text { (2010) }\end{array}$ & $\begin{array}{l}\text { Ind. (whole herd) } \\
\text { Continuous }\end{array}$ & $\begin{array}{l}\text { Whole Herd } \\
\text { Eprinomectin }\end{array}$ & $\begin{array}{l}\text { Reduced } \mathrm{LMM}^{\mathrm{B}} \text { : } \\
6.2(3.1) \\
\text { Full } \mathrm{LMM}^{\mathrm{B}}: \\
3.58(3.24)\end{array}$ & $\begin{array}{l}>1^{\mathrm{C}} \\
>1^{\mathrm{C}}\end{array}$ & $\begin{array}{c}\text { (Interaction) } \\
0.047 \\
0.27\end{array}$ \\
\hline $\begin{array}{l}\text { Charlier } \\
\text { (2007) }\end{array}$ & $\begin{array}{c}\text { Bulk Tank } \\
\text { Categorized }^{C}\end{array}$ & $\begin{array}{l}\text { Whole Herd } \\
\text { Eprinomectin }\end{array}$ & $\begin{array}{l}\text { Largest } 10^{\text {th }} \\
\text { percentile: } \\
4.0(1.53)\end{array}$ & $10^{\text {th }}$ decile $^{\mathrm{C}}$ & 0.03 \\
\hline $\begin{array}{l}\text { Sithole } \\
(2005)\end{array}$ & $\begin{array}{c}\text { Bulk Tank } \\
\text { Dichotomized }\end{array}$ & $\begin{array}{c}\text { Individual } \\
\text { Near Calving } \\
\text { Eprinomectin }\end{array}$ & $\begin{array}{l}\text { Final } \mathrm{LMM}^{\mathrm{B}} \text { : } \\
0.385(0.366)\end{array}$ & $>0.5^{\mathrm{C}}$ & $\begin{array}{c}\text { (Interaction) } \\
0.149\end{array}$ \\
\hline $\begin{array}{l}\text { Sanchez } \\
(2005)\end{array}$ & $\begin{array}{l}\text { Ind. (whole herd) } \\
\text { Continuous }\end{array}$ & $\begin{array}{c}\text { Individual } \\
\text { Near Calving } \\
\text { Eprinomectin }\end{array}$ & $\begin{array}{l}\text { Plotted quadratic } \\
\text { terms }\left(\mathrm{LMM}^{\mathrm{B}}\right) \text { : } \\
\sim 3^{\mathrm{E}}\end{array}$ & $>0.5^{\mathrm{C}}$ & $\begin{array}{l}\text { (Interaction) } \\
\quad<0.05\end{array}$ \\
\hline $\begin{array}{l}\text { Sanchez } \\
(2002)\end{array}$ & $\begin{array}{l}\text { Ind. } \\
\text { (partial herd) } \\
\text { Dichotomized }^{\mathrm{C}}\end{array}$ & $\begin{array}{l}\text { Individual } \\
\text { Near Calving } \\
\text { Eprinomectin }\end{array}$ & $\begin{array}{l}\text { Final } \mathrm{LMM}^{\mathrm{B}} \text { : } \\
2.99(1.66)\end{array}$ & $>0.5^{\mathrm{C}}$ & $\begin{array}{c}\text { (Interaction) } \\
0.07\end{array}$ \\
\hline $\begin{array}{l}\text { Kloosterman } \\
\text { (1996) }\end{array}$ & $\begin{array}{c}\text { Bulk Tank } \\
\text { Dichotomized }^{\mathrm{D}}\end{array}$ & $\begin{array}{l}\text { Individual } \\
\text { Dry Period } \\
\text { Ivermectin }\end{array}$ & $\begin{array}{l}\text { Least square } \\
\text { means: } \\
0.57^{\mathrm{F}}\end{array}$ & $\operatorname{High}^{\mathrm{D}}$ & 0.21 \\
\hline $\begin{array}{c}\text { Ploeger } \\
(1990)\end{array}$ & $\begin{array}{l}\text { Ind. }(5 \text { random } / \mathrm{h}) \\
\text { Continuous } \\
(\text { Range } 4.0-8.5)^{\mathrm{D}}\end{array}$ & $\begin{array}{l}\text { Individual } \\
\text { Near Calving } \\
\text { Albendazole }\end{array}$ & \multicolumn{3}{|c|}{$\begin{array}{c}\text { Reported as: "No significant correlations were found } \\
\text { between the treatment response per herd and the } \\
\text { serological parameters measuring nematode } \\
\text { infection." D }\end{array}$} \\
\hline $\begin{array}{l}\text { Ploeger } \\
(1989)\end{array}$ & $\begin{array}{l}\text { Ind. (5 random } / \mathrm{h}) \\
\text { Continuous }^{\mathrm{D}}\end{array}$ & $\begin{array}{l}\text { Individual } \\
\text { Near Calving } \\
\text { Ivermectin }\end{array}$ & $\begin{array}{l}\text { Linear } \\
\text { Regression: } \\
0.528(0.251)^{\mathrm{F}}\end{array}$ & $\begin{array}{c}\text { Increments of } 1^{\mathrm{D}} \\
\text { (range } 3.8-8.0 \text { ) }\end{array}$ & $\begin{array}{l}\text { (Interaction) } \\
\quad<0.05\end{array}$ \\
\hline
\end{tabular}

Ind.=Individual; BT=Bulk Tank

LMM: Linear Mixed Model

Optical Density Ratios (ODRs)

Serum is initially diluted 1:20; then titre value was the highest dilution that gave a positive

(e.g. $1=1 / 20,2=1 / 40,3=1 / 80$, etc.)

As described in conclusions, and estimated from graph ( $\mathrm{kg}$ milk/cow/day vs. ODR, by treatment)

Converted from standardized $\mathrm{kg} / 305 \mathrm{~d}$ as reported in The Netherlands 
Table 2. Data contributions from all three studies in the IPDMA.

\begin{tabular}{lcccc}
\hline & Field Trial & Sanchez et al. (2002) & Sanchez et al. (2005) & Overall \\
\hline \multicolumn{1}{c}{ Date } & May 2007 to & September 1999 to & February 2002 to & September 1999 to \\
June 2008 & October 2000 & February 2003 & June 2008 \\
Herds (n) & 38 & 26 & 29 & 93 \\
Cows (n) & 1,088 & 101 & 829 & 2,018 \\
eated (n [\%]) & $546[50.2]$ & $51[50.5]$ & $423[51.0]$ & $1,020[50.5]$ \\
II Samples (n) & 8,254 & 846 & 3,424 & 12,524 \\
JIM (mean) & 157.8 & 156.1 & 90.3 & 142.1 \\
JDR (mean) & 0.307 & 0.517 & 0.291 & 0.311 \\
DR selection & Latest single & Averaged within & Averaged within & \\
ior to calving & value & 90days & 150days & \\
isture Access & At least some & At least some & Limited to none & \\
\hline
\end{tabular}


Table 3. Field trial final multilevel mixed model predicting milk loss, containing herd, cow, and test date as random effects, with fixed effects accounting for milk production, questionnaire predictors, and interaction terms (fractional polynomials). The assumed residual structure was AR1, and the model contains 37 herds, 1,088 cows, and 8,254 observations for milk yields ( $\mathrm{kg} / \mathrm{cow} /$ day).

\begin{tabular}{|c|c|c|c|c|}
\hline \multicolumn{5}{|l|}{ Fixed effects } \\
\hline Variable & $\beta$ & $S E$ & $95 \% \mathrm{CI}$ & $P$ \\
\hline Intercept & 144.311 & 3.393 & $137.660,150.961$ & 0.000 \\
\hline Time Period & & & & $<0.001$ \\
\hline Grazed 2007 & Baseline & & & \\
\hline Shoulder 2007 & -0.622 & 0.370 & $-1.347,0.104$ & 0.093 \\
\hline Housed 2008 & 0.622 & 0.436 & $-0.232,1.476$ & 0.153 \\
\hline Grazed 2008 & 0.714 & 0.515 & $-0.294,1.723$ & 0.165 \\
\hline Shoulder 2008 & -0.308 & 0.611 & $-1.506,0.890$ & 0.614 \\
\hline \multicolumn{2}{|l|}{ Calving Season } & & & $<0.001$ \\
\hline Grazed & Baseline & & & \\
\hline Shoulder & 1.692 & 0.397 & $0.915,2.470$ & $<0.001$ \\
\hline Housed & 1.234 & 0.451 & $0.351,2.118$ & 0.006 \\
\hline \multicolumn{2}{|l|}{ Lactation Group } & & & $<0.001$ \\
\hline $2^{\text {nd }}$ & Baseline & & & \\
\hline $3^{\text {rd }}$ & 2.193 & 0.398 & $1.413,2.973$ & $<0.001$ \\
\hline $4^{\text {th }}$ and greater & 2.014 & 0.372 & $1.284,2.744$ & $<0.001$ \\
\hline \multicolumn{2}{|l|}{ Days in milk } & & & $<0.001$ \\
\hline DIM centered & -0.119 & 0.002 & $-0.123,-0.114$ & $<0.001$ \\
\hline $\mathrm{DIM}^{-0.05}$ & -139.806 & 4.058 & $-147.760,-131.852$ & $<0.001$ \\
\hline Log Somatic Cell Count & -0.950 & 0.054 & $-1.057,-0.844$ & $<0.001$ \\
\hline \multicolumn{5}{|l|}{ Anthelmintic Used } \\
\hline Before? & 2.027 & 1.036 & $-0.004,4.057$ & 0.050 \\
\hline \multicolumn{2}{|c|}{ ODR and Treatment Interaction $^{\S}$} & & & $0.138 *$ \\
\hline \multicolumn{5}{|l|}{ Random Effects } \\
\hline Level & Variance & $S E$ & Rho $(\rho)$ & \\
\hline Herd & 6.545 & 1.758 & & \\
\hline Cow & 16.505 & 1.306 & & \\
\hline Residual (AR1) & 30.713 & 0.901 & 0.462 & \\
\hline
\end{tabular}


Table 4. IPDMA final multilevel mixed model predicting milk loss, containing herd, cow, and test date as random effects, with fixed effects accounting for milk production, and interaction terms (fractional polynomials). The assumed residual structure was AR1, and the model contains 87 herds, 2,018 cows, and 12,524 observations for milk yield ( $\mathrm{kg} / \mathrm{cow} / \mathrm{day})$.

\begin{tabular}{|c|c|c|c|c|}
\hline \multicolumn{5}{|l|}{ Fixed effects } \\
\hline Variable & $\beta$ & $S E$ & $95 \% \mathrm{CI}$ & $P$ \\
\hline Intercept & 150.813 & 2.946 & $145.040,156.586$ & $<0.001$ \\
\hline \multicolumn{4}{|l|}{ Time Period } & $<0.001$ \\
\hline Shoulder 1999 & Baseline & & & \\
\hline Housed 2000 & -1.781 & 1.254 & $-4.240,0.678$ & 0.156 \\
\hline Grazed 2000 & -2.292 & 1.308 & $-4.854,0.271$ & 0.080 \\
\hline Shoulder 2000 & -1.951 & 1.374 & $-4.645,0.743$ & 0.156 \\
\hline Housed 2001 & -1.830 & 1.607 & $-4.981,1.320$ & 0.255 \\
\hline Grazed 2002 & 0.293 & 1.619 & $-2.881,3.466$ & 0.857 \\
\hline Shoulder 2002 & -0.752 & 1.592 & $-3.872,2.368$ & 0.637 \\
\hline Housed 2003 & -0.277 & 1.595 & $-3.403,2.848$ & 0.862 \\
\hline Grazed 2003 & -0.742 & 1.643 & $-3.963,2.479$ & 0.652 \\
\hline Grazed 2007 & 1.112 & 1.468 & $-1.766,3.989$ & 0.449 \\
\hline Shoulder 2007 & 0.575 & 1.439 & $-2.247,3.396$ & 0.690 \\
\hline Housed 2008 & 1.987 & 1.439 & $-0.833,4.806$ & 0.167 \\
\hline Grazed 2008 & 2.238 & 1.450 & $-0.604,5.080$ & 0.123 \\
\hline Shoulder 2008 & 1.402 & 1.474 & $-1.486,4.290$ & 0.341 \\
\hline \multicolumn{4}{|l|}{ Calving Season } & $<0.001$ \\
\hline Grazed & Baseline & & & \\
\hline Shoulder & 1.177 & 0.368 & $0.455,1.899$ & 0.001 \\
\hline Housed & 1.286 & 0.296 & $0.706,1.866$ & $<0.001$ \\
\hline \multicolumn{4}{|l|}{ Lactation Group } & $<0.001$ \\
\hline $2^{\text {nd }}$ & Baseline & & & \\
\hline $3^{\text {rd }}$ & 2.360 & 0.304 & $1.764,2.957$ & $<0.001$ \\
\hline $4^{\text {th }}$ and greater & 2.238 & 0.291 & $1.668,2.808$ & $<0.001$ \\
\hline \multicolumn{4}{|l|}{ Days in milk } & $<0.001$ \\
\hline DIM centered & -0.123 & 0.002 & $-0.126,-0.119$ & $<0.001$ \\
\hline $\mathrm{DIM}^{-0.05}$ & -145.072 & 3.153 & $-151.253,-138.891$ & $<0.001$ \\
\hline$\underline{\text { Log Somatic Cell Count }}$ & -1.016 & 0.044 & $-1.103,-0.929$ & $<0.001$ \\
\hline \multicolumn{4}{|c|}{ ODR and Treatment Interaction $^{\S}$} & $0.009 *$ \\
\hline \multicolumn{5}{|l|}{ Random Effects } \\
\hline Level & Variance & $S E$ & Rho $(\rho)$ & \\
\hline Herd & 11.811 & 2.226 & & \\
\hline Cow & 17.055 & 1.037 & & \\
\hline Residual (AR1) & 29.733 & 0.719 & 0.443 & \\
\hline
\end{tabular}

${ }^{\S}$ FP structure of treatment and ODR are described in text and displayed graphically

* Likelihood Ratio Test between the full (displayed in this table) and the reduced model (not shown) 


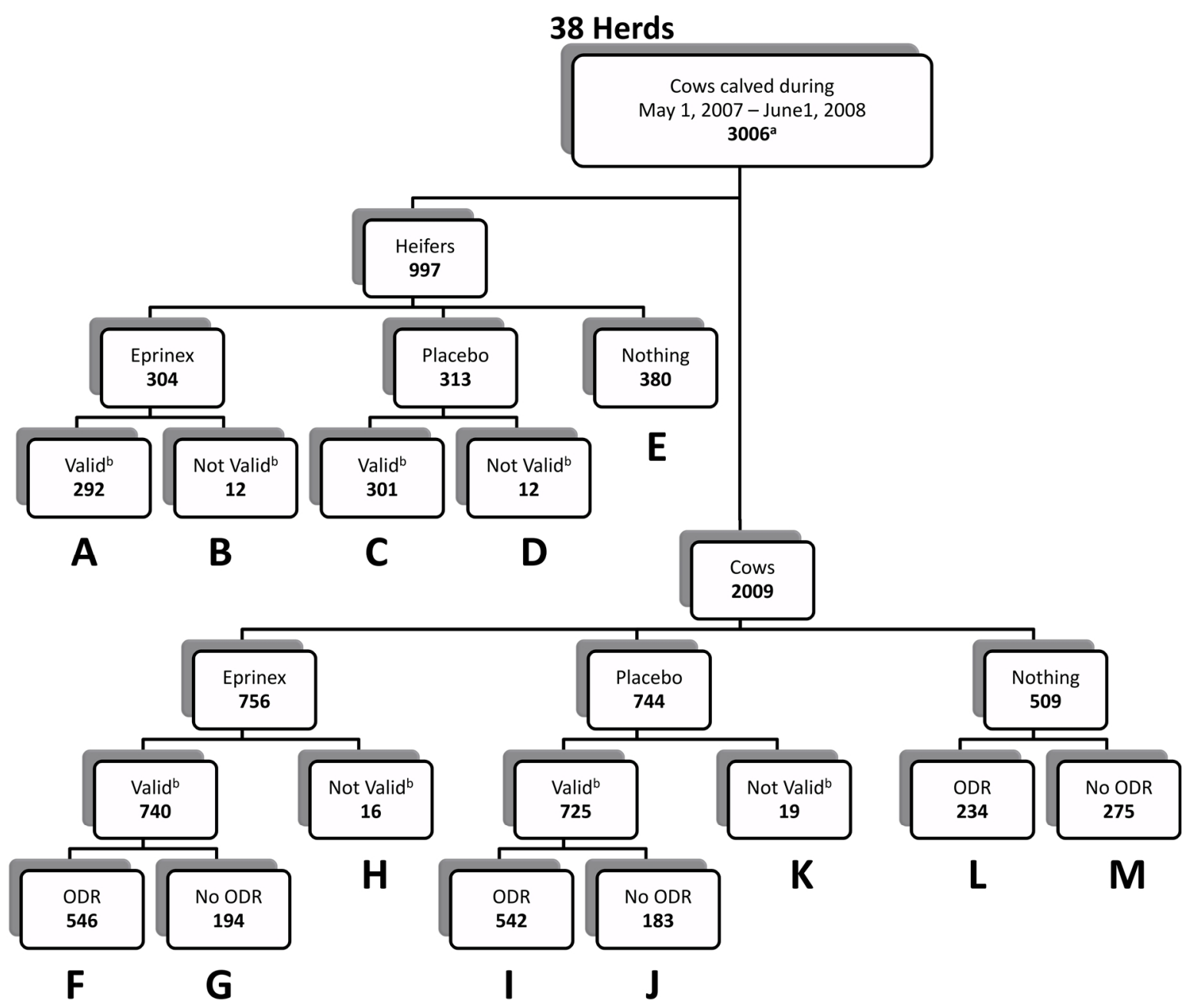

a Counts represent one cow-lactation

${ }^{b}$ Valid refers to receiving the treatment within 2 weeks pre- and 3 days post-parturition

Figure 1. Flow chart of subjects within the field trial evaluating the effect of parasite load on milk production. The diagram shows the final allocation of cows and heifers grouped by treatment and data completeness. ( $\mathrm{n}=$ bold number in each cell) 

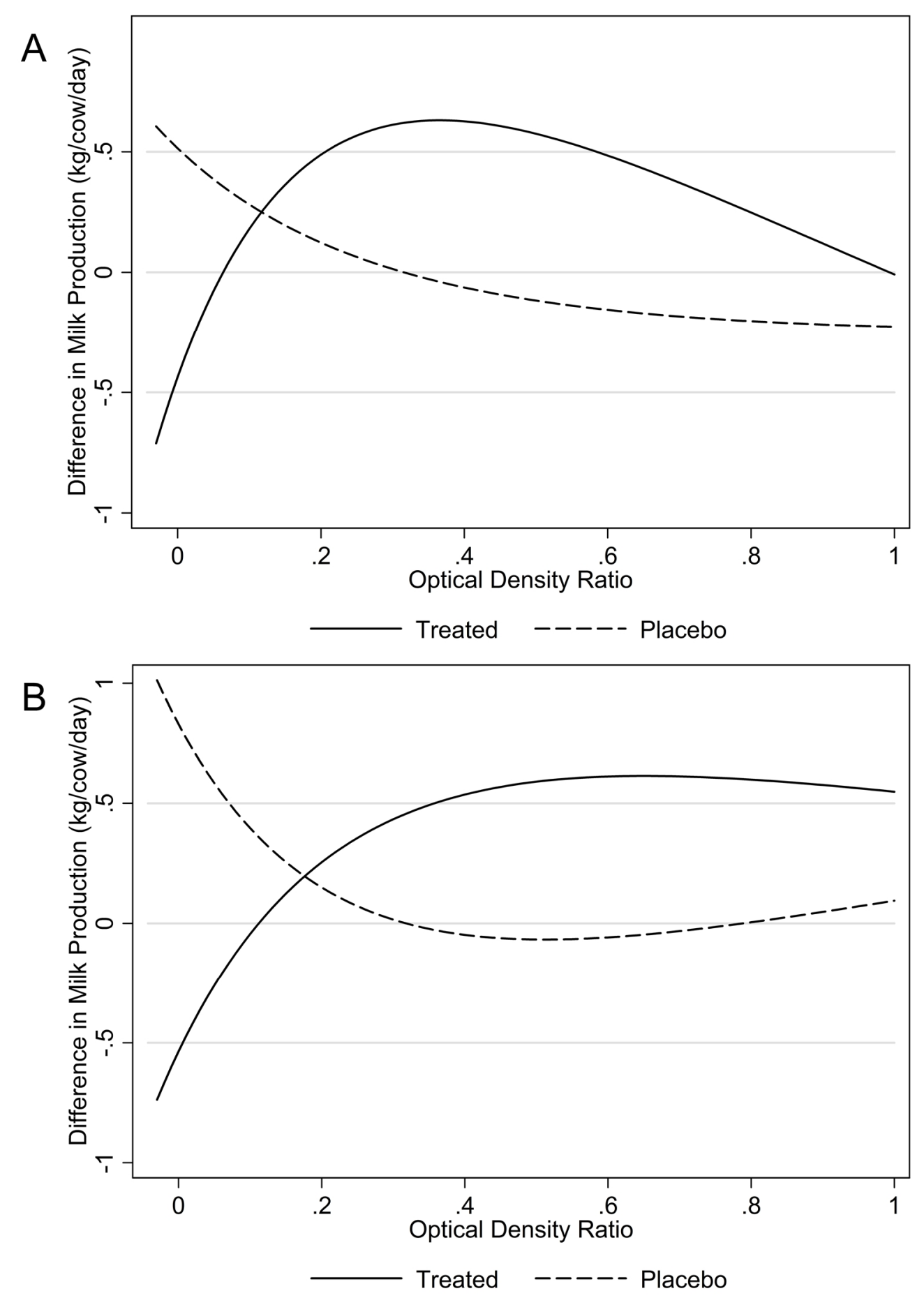

Figure 2. Interaction plot for the treatment and placebo predictions of milk production (yaxis) versus ODR values (x-axis) for the field trial (A) and the IPDMA (B). Specifically, the $\mathrm{y}$-axis shows the normalized milk production values, where zero represents the average placebo cow milk production ( $\mathrm{kg} / \mathrm{cow} / \mathrm{day})$ when all other predictors in the model are held constant. The range of ODR values includes $95 \%$ of the modeled observations. 
Figure 3. Treatment effect showing the difference between expected treatment and placebo milk production ( $\mathrm{kg} \mathrm{milk/cow/day)} \mathrm{versus} \mathrm{ODR} \mathrm{for} \mathrm{the} \mathrm{field} \mathrm{trial} \mathrm{(A)} \mathrm{and} \mathrm{the} \mathrm{IPDMA} \mathrm{(B).}$ 95\% Confidence Interval bands were calculated and plotted. The range of the ODR values includes $95 \%$ of the modeled observations. 